\title{
Vittorio Berti. "Logicising Ecclesiastical Conflicts: The Synod of Henanishō' II (775) and the Aristotelian Vogue among East Syrian Scholars"
}

Florence Jullien

\section{(2) OpenEdition}

Journals

Édition électronique

URL : https://journals.openedition.org/abstractairanica/54186

DOI : 10.4000/abstractairanica.54186

ISSN : 1961-960X

Éditeur :

CNRS (UMR 7528 Mondes iraniens et indiens), Éditions de l'IFRI

Référence électronique

Florence Jullien, « Vittorio Berti. "Logicising Ecclesiastical Conflicts: The Synod of Henanīshō‘ II (775) and the Aristotelian Vogue among East Syrian Scholars" », Abstracta Iranica [En ligne], Volume 42-43 | 2021, document 30, mis en ligne le 30 décembre 2021, consulté le 15 décembre 2022. URL : http:// journals.openedition.org/abstractairanica/54186; DOI : https://doi.org/10.4000/abstractairanica. 54186

Ce document a été généré automatiquement le 15 décembre 2022.

Tous droits réservés 


\title{
Vittorio Berti. "Logicising
} Ecclesiastical Conflicts: The Synod of Henanishō' II (775) and the Aristotelian Vogue among East Syrian Scholars"

\author{
Florence Jullien
}

\section{RÉFÉRENCE}

Vittorio Berti. "Logicising Ecclesiastical Conflicts: The Synod of Ḥenanīshō‘ II (775) and the Aristotelian Vogue among East Syrian Scholars", Journal of Eastern Christian Studies 72/3-4, 2020, p. 203-215.

1 L'A., spécialiste de l'histoire de l'Église d'Orient sous le califat abbasside, livre ici une réflexion sur l'importance de l'héritage grec, plus spécifiquement de l'enseignement aristotélicien chez les lettrés syro-orientaux. La mise en place de ce synode en 775 par Ḥenanī̌ō ${ }^{`}$ II se déroule à une période de transition alors que la dynastie abbasside est au pouvoir depuis 25 ans. Il s'agit aussi du premier synode réuni depuis l'instauration du nouveau pouvoir, après une longue vacance du siège patriarcal - le dernier s'étant tenu en 680 sous le gouvernorat de Mār Guiwarguis I ${ }^{\text {er }}$ (661-680/1). Le paysage politique mais aussi la territorialisation juridictionnelle ne sont plus les mêmes puisque l'empire s'étend désormais jusqu'à la Méditerranée et que la capitale abbasside est replacée au cœur de la Babylonie.

2 L'A. souligne l'importance sociale acquise par les élites de langue syriaque notamment ecclésiastiques en raison de leurs compétences littéraires et scientifiques acquises grâce à la paideia hellénisante transmise dans les monastères depuis l'époque sassanide. Cette dynamique culturelle expliquerait le recours volontaire à un vocabulaire logique 
emphatique dans le texte du synode. V. Berti participe par ailleurs au vaste programme international d'édition des synodes orientaux coordonné par A. Melloni (Université de Bologne) et la Fondation Fscire pour le Corpus Christianorum chez Brepols dans lequel il a précisément en charge les actes du concile de 585 sous Ḥenaniššç II.

\section{AUTEURS}

FLORENCE JULLIEN

CNRS, CeRMI, Paris 